\title{
Gerta Vrbová, a guide and a friend for a generation of neuro- myologists - Her scientific legacies and relations with colleagues
}

\author{
Ugo Carraro
}

Department of Biomedical Sciences, University of Padova, Italy; CIR-Myo - Interdepartmental Research Center of Myology, University of Padova, Italy; A\&C M-C Foundation for Translational Myology, Padova, Italy.

This article is distributed under the terms of the Creative Commons Attribution Noncommercial License (CC BY-NC 4.0) which permits any noncommercial use, distribution, and reproduction in any medium, provided the original author(s) and source are credited.

\begin{abstract}
Gerta Sidonová - Vrbová, (Trnava, Slovakia, November 28, 1926 - London, UK, October 2, 2020) has been a key neuroscientist, who for almost half a century has contributed important findings and hypotheses on the relationships between motoneurons and skeletal muscle fibers, in particular on the differentiation and extent of plasticity of the peculiar characteristics of the different types of fibers present in mammalian muscles. This issue, Ejtm 31 (1), 2021, opens with the personal obituary authored by Dirk Pette, who remember his lifelong collaboration with Gerta, describing the many molecular and metabolic events that occur by changing the pattern of activation of adult muscle fibers through neuromuscular low frequency electrical stimulation. To honor the many scientific legacies of Gerta Vrbová and her impact on a generation of researchers studying myology and managements of neuromuscular disorders I add here additional examples of Gerta's scientific heritage and of her relations with colleagues.
\end{abstract}

Key Words: Gerta Vrbová; muscle development differentiation and plasticity; discharge patterns of motoneurons; electrical stimulation of skeletal muscles.

Eur J Transl Myol 31 (1): 9670, 2021 doi: 10.4081/ejtm.2021.9670

Gerta Sidonová -Vrbová, Trnava (Slovakia) November 28, 1926 - London (UK) October 02, 2020.

Gerta Vrbová was a key neuroscientists who for more than half-century contributed results and hypotheses on the mutual relations between motoneurons and skeletal muscle fibers, i.e., about differentiation and maintenance of the characteristics of the motoneurons and of the muscle fiber types of mammalian muscles. Implication and transfer of her personal conclusions to managements of neuromuscular disorders were her second main interest. Gerta Vrbová made a career out of studying nerves, though her own were made of steel. Twice she escaped brutal regimes: once by jumping from a window to flee the Nazis, and later by crossing from Czechoslovakia to Poland on foot with two young children in tow to escape the communists. Her troubles began in her home town of Trnava, in western Slovakia, in 1939. Jewish people faced discrimination and the 12year-old was excluded from school. Rudi Vrba, an old school friend who was two years her senior, helped with her studies. She recalled a bicycle trip one summer day in 1939 with another friend, Marushka, who announced that they could no longer meet because Gerta was Jewish. We leave to others to stress the courage and determination of Gerta to achieve scientific results and to overcome tremendous personal obstacle along her long life., ${ }^{1,2}$ This issue, Ejtm 31 (1), 2021, opens with the personal obituary authored by Dirk Pette who remember his lifelong collaboration with Gerta, describing the many molecular and metabolic events that occur by changing the pattern of activation of adult muscle fibers through neuromuscular low frequency electrical stimulation. ${ }^{3}$

To honor Gerta Vrbová and her scientific legacy, I add below my own memories. I meet Gerta for the first time in 1980, when she was visiting Prof. Massimiliano Aloisi at the Institute of General Pathology of the University of Padova, Italy. As the last young fellow of Prof. Aloisi, I was invited to present her my first-name paper on long term denervated rat hem-diaphragm. ${ }^{4}$ She was very pleased to hear that in the six-month denervated hemidiaphragm (a very mixed muscle) almost only fast-type Myosin Light Chains were present, a molecular result fully in agreement with the Gerta's seminal observations that denervation, depriving the slow-type muscle fibers of the continuous stimulation of the slow-type motoneurons, shortened the contraction time of the slowtype muscles. ${ }^{5-7}$ Her warm attention was the main support to my commitment to continue those studies during the following decades, independently from other 


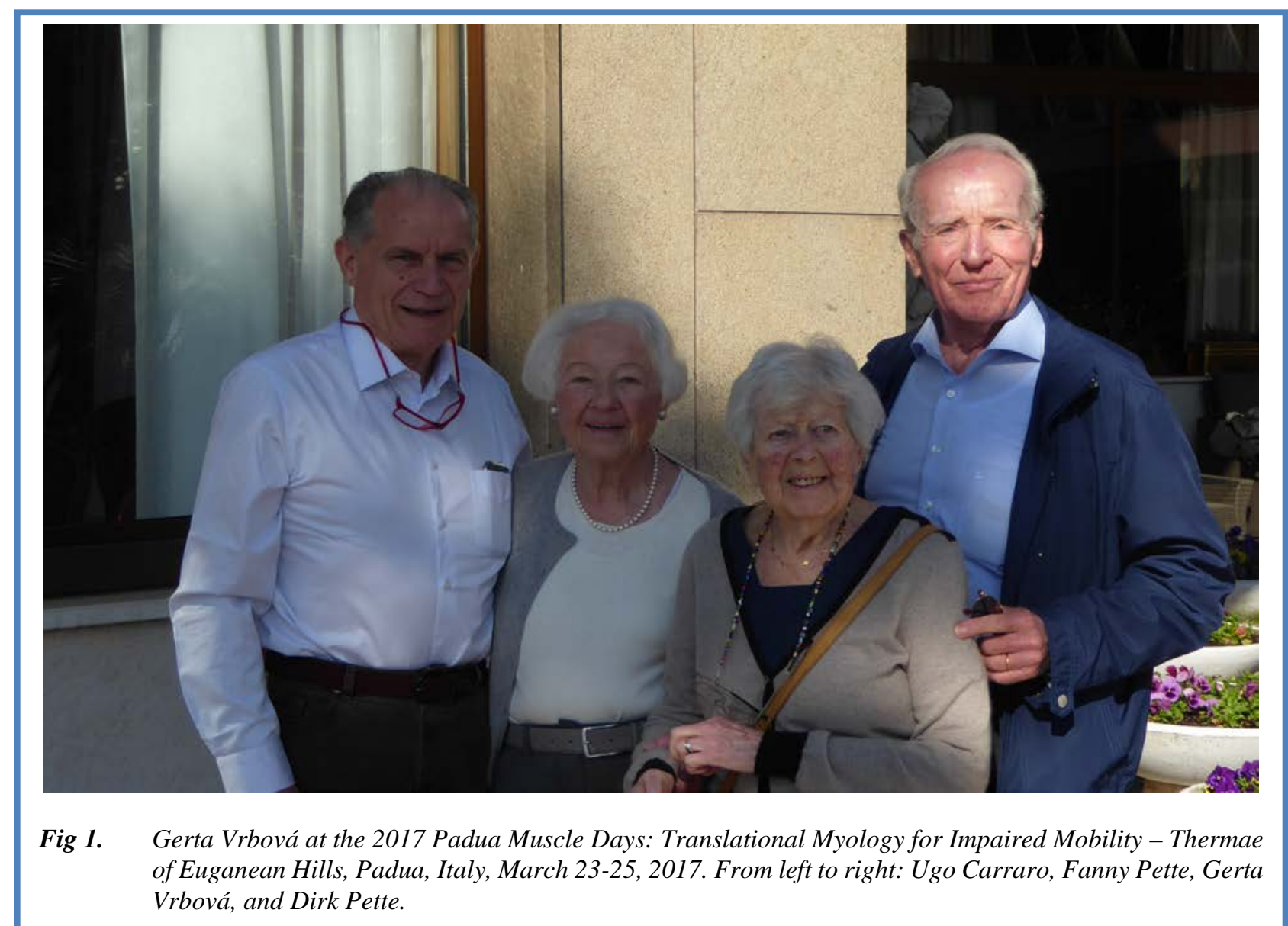

international researchers, but heartened from many concordant results of prestigious groups, including, beside Gerta and Dirk Pette, ${ }^{8-10}$ Stanley Salmons, ${ }^{11-13}$ and Terje Lomo. ${ }^{14-20}$ Specifically, Terje had pioneered, often in collaboration with Stefano Schiaffino, ${ }^{21}$ the experimental model of low-frequency full-day electrical stimulation of denervated muscle in the rat model, to avoid the criticism that, stimulating the nerve, an antidromic adaptation of the motoneurons may occur before transformation of the innervated muscle fibers of the motor units. Further strong evidence negating that option were convincingly discussed by Terje Lømo during a Lecture at the 2014 Padua Muscle Days. ${ }^{22}$

The criticisms of course remained that our observations were restricted to the denervated hemi-diaphragm, a peculiar experimental model in which the denervated muscle fibers continued to be passively stretched by the innervated contralateral hemi-diaphragm. Encouraged by the suggestion of Gerta that that was further evidence that the denervated muscle fibers were able to respond to induced passive-stretch in absence of direct contact with the motoneuron terminals and by the accumulating evidence that the muscle fibers may develop and partly differentiate in vitro in the absence of neural contacts [see for a recent short account of the history of this topic $]^{23,24}$ soon after the visit of Gerta to Padova, we firstly extended our observations to long term denervated and reinnervated leg muscles, ${ }^{25}$ then in a conclusive paper in the Journal of Cell Biology (1985), ${ }^{26}$ we demonstrated a substantial slow to fast transformation of the denervated rat hemi-diaphragm by electron microscopy analyses (evidence of severely decreased mitochondria, pathological features of membranes of sarcoplasmic reticulum (SR) and regeneration of muscle fibers), by single fibers analyses of myosin heavy chains (MHC) (evidence that MHC of fast type accumulate at the expense of the slow type) and by 2D SDS Gel electrophoresis of myosin light chains (MLC) and parvalbumin (again, clear prevalence of the fast type characteristics). With our surprise, we were able to analyze a large numbers of muscle fibers up to 16 months after phrenectomy. ${ }^{26}$ All those results indicated that, after reaching a severe atrophic status 3 months after denervation, all types of denervated muscle fibers: i) maintain a residual $10 \%$ mass; ii) resting fast fibers continue to show their features, while iii) previously slow fibers acquire partially or almost completely fast type molecular characteristics.

In 1986, under the influence of results of Terje Lømo, we developed an independent experimental model of electrical stimulation of denervated rat leg muscle, showing that the fast muscle fibers of the fast-type extensor digitorum longus (EDL) rat muscle, submitted to continuous slow-like electrostimulation, switch-on the 
genes of slow myosin in denervated fast-type muscle fibers. ${ }^{27}$ Thus, adult fast and slow skeletal muscles are composed of a large number of fibers with different physiological and biochemical properties that under neuronal control can respond in a plastic manner to a variety of stimuli. Although muscle cells synthesize muscle-specific contractile proteins in the absence of motoneurons, after innervation the type of motoneuron controls the particular set of isoforms subsequently synthesized. However, agreement had not been reached on the mechanism, either chemotrophic or impulsemediated, by which the nerve influences gene expression of the skeletal muscle fibers. In that study, ${ }^{27}$ we reported the effect on isomyosins of continuous, low-frequency (a protocol mimicking the discharge pattern of the slow motoneuron) direct electrical stimulation of a permanently denervated fast muscle, the extensor digitorum longus of adult rat. After several weeks, unlike sham-stimulated muscle, the stimulated muscle showed a dramatic increase of the slow myosin light and heavy chains. Myosin light chains were identified by twodimensional gel electrophoresis. The slow myosin heavy chains were clearly distinguished from fast and embryonic types by one-dimensional sodium dodecyl sulfate-polyacrylamide gel electrophoresis and orthogonal peptide mapping. The myosin changes could be restricted to a portion of the muscle by the position of the stimulating electrodes. Taking into account the morphologic appearance of the electrostimulated muscle and the large body of evidence demonstrating the absolute dependence of slow myosin on specific innervation, our observations indicated that at least the slow motoneuron influences the isomyosin genes' expression by the kind of activity it imposes on developing muscle fibers. I am still wondering if the protocol we used in Padova, that was able to induce in the denervated fast-type EDL of rats high levels of expression of slow-type light and heavy chains found their rational in the fact that we increased the current duration of each impulse from 0.4 to 4.0 milliseconds. ${ }^{27}$ Meantime Gerta Vrbová and Stanley Salmons proposed the use of electrical stimulation to increase resistance to fatigue of skeletal muscles for different managements of neuromuscular disorders, among others Duchenne Muscular Dystrophy, ${ }^{28,29}$ and for the support of insufficient circulation by Cardiomyoplasty, ${ }^{30}$ or of sphincter muscles. ${ }^{31}$ Meanwhile, electrical stimulation of the diaphragm has become an accepted clinical approach for patients with respiratory paralysis and intact phrenic nerves. Indeed, continuous simultaneous pacing of both hemi diaphragms with low-frequency stimulation and a slow respiratory rate is a satisfactory method of providing full-time ventilation support. ${ }^{32-36}$ In collaboration with the University of Bologna (Italy), we have been involved in a ten-year research project on cardiomyoplasty, testing the concept of dynamic cardiomyoplasty on demand. We were inspired by the differential effects on the contractile properties, population of fibers, myosin light chains and enzymes of energy metabolism of different periods of intermittent or continuous electrical stimulation of fasttwitch muscles (Gerta Vrbová and Dirk Pette). ${ }^{37}$ Both in normal sheep, ${ }^{38}$ and in patients suffering with chronic heart failure, the latissimus dorsi responded to daily intermittent electrical stimulation reaching intermediate contractile characteristics during its fast lo slow transition induced be the on Demand (intermittent) stimulation protocol. ${ }^{39}$ The partially maintained fast type contractions of the patient muscle wrapped around the falling heart allowed to synchronize the pace-makerinduced tetanic contractions with the heart systole, avoiding interference with the diastolic function. Specifically, during assisted systolic contractions cardiac ejection fractions of heart failure patients were increased. ${ }^{40-42}$

Always supported by interest and suggestions of Gerta, from 2000, in collaboration with Prof. Helmut Kern of Vienna (Austria) we were able to show in a study supported by the EU Commission [(RISE - Use of electrical stimulation to restore standing in paraplegics with long-term denervated degenerated muscles (QLG5CT-2001-02191)] that a home-base protocol using long currents (up to 150 milliseconds) is able to reverse severe atrophy of permanent denervated human muscles, up to a level to allow stimulation-induced standing and pacingin-place exercise. ${ }^{43-49}$ For an example see the supplementary material in Kern H, Carraro U (2020) ${ }^{50}$ : Home-based Functional Electrical Stimulation (hbFES) assisted stand-up exercise. ${ }^{51}$

One of the effects of spinal cord injury (SCI) is rapid loss of contractile force and muscle mass, but atrophy of leg muscles is particularly severe when the injury destroys the soma of the lower motoneurons and, hence, the contacts between skeletal muscle fibers and motoneurons are permanently lost. Within weeks after SCI, muscles become unable to sustain tension during tetanic contractions induced by electrical stimulation. ${ }^{52-54}$ Within months after a complete injury of the conus medullaris and cauda equina, the muscles are no longer excitable by commercially available electrical stimulators. ${ }^{55}$ This is because they have undergone severe disorganization of contractile elements (i.e., of the myofibrils) and of the excitation-contraction coupling (ECC) apparatuses. Finally, after several years of LMN denervation, human muscle fibers are almost completely replaced by adipose and fibrous tissues. ${ }^{44-46}$ This severe degeneration of muscle tissue does not occur in patients with upper motoneuron lesions even 20 years after thoracic-level SCI. ${ }^{56}$ To substantiate the functional and molecular mechanisms that allow muscle fibers to survive long-term denervation, we meantime performed experiments in a rat model of long-term denervation by analyses not possible in humans for obvious ethical concerns. The results are summarized in the abstract of a paper published by Squecco R, et al. (2009). ${ }^{57}$

To define the time course and potential effects of electrical stimulation on permanently denervated 
muscles, we evaluated ECC of rat leg muscles during progression to long-term denervation by ultrastructural analysis, specific binding to dihydropyridine receptors, ryanodine receptor 1 (RYR-1), $\mathrm{Ca}^{2+}$ channels and extrusion $\mathrm{Ca}^{2+}$ pumps, gene transcription and translation of $\mathrm{Ca}^{2+}$-handling proteins, in vitro mechanical properties and electrophysiological analyses of sarcolemmal passive properties and L-type $\mathrm{Ca}^{2+}$ current (ICa) parameters. We found that in response to long-term denervation: i) isolated muscle that is unable to twitch in vitro by electrical stimulation has very small myofibers but may show a slow caffeine contracture; ii) only roughly half of the muscle fibers with voltage-dependent $\mathrm{Ca}^{2+}$ channel activity are able to contract; iii) the ECC mechanisms are still present and, in part, functional; iv) ECC-related gene expression is upregulated; and v) at any time point, there are muscle fibers that are more resistant than others to denervation atrophy and disorganization of the ECC apparatus. These results support the hypothesis that prolonged "resting $\left[\mathrm{Ca}^{2+}\right]$ " may drive progression of muscle atrophy to degeneration and that electrical stimulation-induced $\left[\mathrm{Ca}^{2+}\right]$ modulation may mimic the lost nerve influence, playing a key role in modifying the gene expression of denervated muscle. Hence, these data provide a molecular explanation for the muscle recovery that occurs in RISE SCI patients in response to the rehabilitation strategies developed on the grounds of empirical clinical observations. ${ }^{44-51}$

Gerta maintained her interest for the myology activities of the Interdepartmental Research Center of Myology of the University of Padova (CIR-Myo), even after she was more than 85 years old. Our relations were strengthened, indeed, after we discovered (getting out from a night bus after a dinner in Central London) that she was living in Muswell Hill just 10 walking-minutes from the house of my son's family.

She joined several times the PaduaMuscleDays, a meeting mainly devoted to translational research for skeletal muscle biology, management and rehabilitation. Last time it was in 2017, when she went together with Dirk Pette. During that meeting she accepted also to be interviewed on the importance for old people to stay physically and mentally active. She was, indeed, a witness (and herself a strong evidence, being in her ninety years) of the value of a very active life for the oldest olds. Readers may follow her advices at the YOUTUBE link: ${ }^{58}$

https://www.youtube.com/watch?v=NJ9BPLquPWw

During her career Gerta Vrbová published more than 270 scientific papers, but her main role was to inspire a generation of successful researchers. Some were her postdoctoral fellows Maggie Lowrie, ${ }^{59}$ Angela Connold, ${ }^{60}$ Linda Greensmith, ${ }^{61}$ Roberto Naverrete, ${ }^{62}$ Antal Nógrádi, ${ }^{63}$ and Katarzyna Sieradzan ${ }^{64}$, but independent scientists, among which I mention researchers studying nerve regeneration after partial or complete nerve injuries (Tessa Gordon, Canada) ${ }^{65}$ electrical stimulation and muscle plasticity (Dirk Pette,
Germany), ${ }^{3,8,9,66}$ electrical stimulation of denervated muscle in animal models, e.g., Terje Lomo, Norway, ${ }^{67}$ and myself in Italy, working in both animal models and humans, ${ }^{68}$ and finally aging human muscles (Helmut Kern, Austria). ${ }^{69}$ Many of her pupils were brilliant enough to continue independent scientific careers and make major contributions to the fields of neuron diseases and injury, including amyotrophic lateral sclerosis and spinal muscular atrophy (Linda Greensmith in London), ${ }^{61}$ Parkinson's, Huntington's and Pompe diseases and epilepsy (Katarzyna Sieradzan in Bristol), ${ }^{64}$ ventral root avulsion (Antal N Nógrádi in Szeged, Hungary) ${ }^{63,70}$ and in the field of locomotion (Urszula Slawinska in Warsaw, Poland). ${ }^{71}$ Her medical background explains her interest in translating experimental results into possible treatments for childhood genetic diseases of muscular dystrophy and spinal muscular atrophy, in collaboration with neurologists, Victor Dubowitz in London, UK, ${ }^{72}$ Milan Dimitrijevic in Houston, USA, ${ }^{73}$ and Irena HausmanovaPetrusewicz in Warsaw, Poland. ${ }^{74}$ Most of the latest opportunities found grounds on just two of her publications that inspired her a working hypothesis that changed the perspectives of interactions between skeletal muscle fibers and motoneurons, starting 50 years of studies still in need of further investigations.

As is often the case in science and even more in translational research, there are now more open questions and hypotheses than before. Firm conclusions for some of the above discussed topics remain open to further researches, worth of significant founding by international sponsors. What is certain is that Gerta's legacy remains among the key preliminary results for supporting those grant applications.

I will never forget Gerta's friendship and support.

\section{List of acronyms}

CIR-Myo - Interdepartmental Research Center of Myology of the University of Padova

ECC - excitation-contraction coupling

EDL - extensor digitorum longus

EU - European Union

hbFES - Home-based Functional Electrical Stimulation (hbFES)

MHC - myosin heavy chains

MLC - myosin light chains

RISE - Use of electrical stimulation to restore standing in paraplegics with long-term denervated degenerated muscles

RYR-1 - ryanodine receptor 1

SCI - spinal cord injury

SR - sarcoplasmic reticulum

\section{Acknowledgments}

PAGEpress, Scientific Publications, Pavia, Italy sponsored this Obituary.

Funding None 


\section{Conflict of Interest}

The author declares no competing interests.

\section{Ethical Publication Statement}

I confirms that I have read the Journal's position on issues involved in ethical publication and affirms that this report is consistent with those guidelines.

\section{Corresponding Author}

Ugo Carraro, Department of Biomedical Sciences, University of Padova, Via Ugo Bassi, 58/B 35131 Padova, Italy.

E-mail: ugo.carraro@unipd.it

\section{References}

1. Caroline Hilton. The Guardian, International Edition. 2020. Available at: https://www.theguardian.com/theguardian/2020/oc t/19/gerta-vrbova-obituary

2. Gerta Vrbová Obituary, The Times. Monday November 23 2020, 12.01am GMT, Available at: https://www.thetimes.co.uk/checkout?pc=INTL1M THFR10\&_ga=2.106678595.1143194066.161035 0069-418594896.1610350069

3. Dirk Pette. The significance of Gerta Vrbová's lowfrequency stimulation experiment. Eur J Transl Myol. 31 (1): 9585, 2021 doi: 10.4081/ejtm. 2021.9585

4. Carraro U, Catani C, Biral D. Selective maintenance of neurotrophically regulated proteins in denervated rat diaphragm. Exp Neurol. 1979 Mar;63(3):468-75. doi: 10.1016/0014-4886(79)90 165-1

5. Vrbová G. The effect of motoneurone activity on the speed of contraction of striated muscle. J Physiol. 1963 Dec;169(3):513-26. doi: 10.1113/ jphysiol.1963.sp007276.

6. Salmons S, Vrbová G. Changes in the speed of mammalian fast muscle following longterm stimulation. J Physiol. 1967 Sep;192(2):39P-40P.

7. Salmons S, Vrbová G. The influence of activity on some contractile characteristics of mammalian fast and slow muscles. J Physiol. 1969 May;201(3):53549. doi: 10.1113/jphysiol.1969.sp008771.

8. Pette D, Müller W, Leisner WE, Vrbová G. Time dependent effects on contractile properties, fibre population, myosin light chains end enzymes of energy metabolism in intermittently and continously stimulated fast twitch muscles of the rabbit. Plügers Arch. 1976 Jul 30;364(2):103-12. doi: 10.1007/BF00585177.

9. Pette D, Vrbová G. Invited review: neural control of phenotypic expression in mammalian muscle fibers. Muscle Nerve. 1985 Oct;8(8):676-89. doi: 10.1002 /mus.880080810.

10. Pette D, Vrbová G. Adaptations of mammalian muscle fibers to chronic electrical stimulation. Rev Physiol Biochem Pharmacol. 1992; 120: 116-202.
11. Salmons S. An implantable muscle stimulator. J Physiol. 1967 Jan;188(2):13P-14P.;

12. Salmons S, Sreter FA. Significance of impulse activity in the transformation of skeletal muscle type. Nature. 1976 Sep 2;263(5572):30-4. doi: 10.1038/263030a0.

13. Salmons S, Henriksson J. The adaptive response of skeletal muscle to increased use. Muscle Nerve. Mar-Apr 1981;4(2):94-105. doi: 10.1002/mus.8800 40204.

14. Lømo T, Westgaard RH, Dahl HA. Contractile properteies of muscle: control by pattern of muscle activity in the rat. Proc Roy Soc. 1974 Aug 27;187(1086):99-103. doi: 10.1098/rspb.19740064.

15. Lømo T, Westgaard RH. Further studies on the control of ACh sensitivity by muscle activity in the rat. J Physiol. 1975 Nov;252(3):603-26. doi: 10.1113/jphysiol.1975.sp011161.

16. Hennig R, Lømo T. Firing patterns of motor units in normal rats. Nature. 1985 Mar 14-20;314 (6007):164-6. doi: 10.1038/314164a0.

17. Lømo T, Massoulié J, Vigny M. Stimulation of denervated rat soleus muscle with fast and slow activity patterns induces different expression of acetylcholinesterase molecular forms. J Neurosci. 1985 May;5(5):1180-7. doi: 10.1523/JNEUROSCI. 05-05-01180.1985.

18. Gundersen K, Leberer E, Lømo T, Pette D, Staron RS. Effects of chronic stimulation on the size and speed of long-term denervated and innervated rat fast and slow skeletal muscles. J Physiol. 1988 Apr;398:177-89. doi: 10.1113/jphysiol.1988.sp 017037.

19. Gundersen K, Leberer E, Lømo T, Pette D, Staron RS. Fibre types, calcium-sequestering proteins and metabolic enzymes in denervated and chronically stimulated muscles of the rat. J Physiol. 1988 Apr;398:177-89. doi: 10.1113/jphysiol.1988.sp 017037.

20. Windisch A, Gundersen K, Szabolcs MJ, Gruber H, Lømo T. Fast to slow transformation of denervated and electrically stimulated rat muscle. J Physiol. 1998 Jul 15;510 (Pt 2)(Pt 2):623-32. doi: 10.1111/j.1469-7793.1998.623bk.x.

21. Schiaffino S, Reggiani C. Fiber types in skeletal muscles. Physiol Rev. 2011 Oct;91(4):1447-531. doi: 10.1152/physrev.00031.2010..

22. Lømo T. The response of denervated muscle to long-term stimulation (1985, revisited here in 2014. 2014;24 (1):3294. doi: 10.4081/ejtm.2014.3294

23. Singer RH. 2020 Distance Meeting: Farewell to Professor David Yaffe - A pillar of the myogenesis field. Eur J Transl Myol. 2020 Sep 9;30(3):9327. doi: 10.4081/ejtm.2020.9327.

24. Yablonka-Reuveni Z, Stockdale F, Nudel U, Israeli D, Blau HM, Shainberg A, Neuman S, KesslerIcekson G, Krull EM, Paterson B, Fuchs OS, Greenberg D, Sarig R, Halevy O, Ozawa E, Katcoff 
DJ. Farewell to Professor David Yaffe - A pillar of the myogenesis field. Eur J Transl Myol. 2020 Aug 18;30(3):9306. doi: 10.4081/ejtm.2020.9306

25. Carraro U, Catani C, Dalla Libera L. Myosin light and heavy chains in rat gastrocnemius and diaphragm muscles after chronic denervation or reinnervation. Exp Neurol. 1981 May;72(2):40112. doi: 10.1016/0014-4886(81)90232-6

26. Carraro U, Morale D, Mussini I, Lucke S, Cantini M, Betto R, Catani C, Dalla Libera L, Danieli Betto D, Noventa D. Chronic denervation of rat hemidiaphragm: maintenance of fiber heterogeneity with associated increasing uniformity of myosin isoforms. J Cell Biol. 1985 Jan;100(1):161-74. doi: 10.1083/jcb.100.1.161

27. Carraro U, Catani C, Belluco S, Cantini M, Marchioro L. Slow-like electrostimulation switches on slow myosin in denervated fast muscle. Exp Neurol. 1986 Dec;94(3):537-53. doi: 10.1016/ 0014-4886(86)90236-0.

28. Dangain J, Vrbova G. Long term effect of low frequency chronic electrical stimulation on the fast hind limb muscles of dystrophic mice. J Neurol Neurosurg Psychiatry. 1989 Dec;52(12):1382-9. doi: 10.1136/jnnp.52.12.1382.

29. Scott OM, Hyde SA, Vrbová G, Dubowitz V. Therapeutic possibilities of chronic low frequency electrical stimulation in children with Duchenne muscular dystrophy. J Neurol Sci. 1990 Feb;95(2):171-82. doi: 10.1016/0022510x(90)90240-n. PMID: 2324768

30. Salmons S, Jarvis JC. Cardiac assistance from skeletal muscle: a critical appraisal of the various approaches. Br Heart J. 1992 Sep;68(3):333-8. doi: 10.1136/hrt.68.9.333.

31. Russold MF, Ramnarine I, Ashley Z, Sutherland H, Salmons S, Jarvis JC. Practical and effective stomal sphincter creation: evaluation in pigs. Dis Colon Rectum. 2010 Apr;53(4):467-74. doi: 10.1007/DCR.0b013e3181bdbe91.

32. Glenn WW, Phelps ML. Diaphragm pacing by electrical stimulation of the phrenic nerve. Neurosurgery. 1985 Dec;17(6):974-84. doi: 10.1227/00006123-198512000-00021.

33. Glenn WW, Hogan JF, Loke JS, Ciesielski TE, Phelps ML, Rowedder R. Ventilatory support by pacing of the conditioned diaphragm in quadriplegia. $\mathrm{N}$ Engl J Med. 1984 May 3;310(18):1150-5. doi: 10.1056/NEJM1984050 33101804.

34. Skalsky AJ, Lesser DJ, McDonald CM. Evaluation of phrenic nerve and diaphragm function with peripheral nerve stimulation and M-mode ultrasonography in potential pediatric phrenic nerve or diaphragm pacing candidates. Phys Med Rehabil Clin N Am. 2015 Feb;26(1):133-43. doi: 10.1016/j.pmr.2014.09.010.
35. Berger D, Bloechlinger S, von Haehling S, Doehner W, Takala J, Z'Graggen WJ, Schefold JC. Dysfunction of respiratory muscles in critically ill patients on the intensive care unit. J Cachexia Sarcopenia Muscle. 2016 Sep;7(4):403-12. doi: 10.1002/jcsm.12108. Epub 2016 Mar 9.

36. Marrero HDJG, Stålberg EV, Cooray G, Corpeno Kalamgi R, Hedström Y, Bellander BM, Nennesmo I, Larsson L. Neurogenic vs. Myogenic Origin of Acquired Muscle Paralysis in Intensive Care Unit (ICU) Patients: Evaluation of Different Diagnostic Methods. Diagnostics (Basel). 2020 Nov 18;10(11):966. doi: 10.3390/diagnostics10110966.

37. Pette D, Müller W, Leisner E, Vrbová G. Time dependent effects on contractile properties, fibre population, myosin light chains and enzymes of energy metabolism in intermittently and continuously stimulated fast twitch muscles of the rabbit. Pflugers Arch. 1976 Jul 30;364(2):103-12. doi: 10.1007/BF00585177.

38. Arpesella G, Carraro U, Mikus PM, Dozza F, Lombardi P, Marinelli G, Zampieri S, El Messlemani AH, Rossini K, Pierangeli A. Activityrest stimulation of latissimus dorsi for cardiomyoplasty: 1-year results in sheep Ann Thorac Surg. 1998 Dec;66(6):1983-90. doi: 10.1016/s0003-4975(98)00906-0.

39. Carraro U, Barbiero M, Docali G, Cotogni A, Rigatelli G, Casarotto D, Muneretto C. Demand dynamic cardiomyoplasty: mechanograms prove incomplete transformation of the rested latissimus dorsi. Ann Thorac Surg. 2000 Jul;70(1):67-73. doi: 10.1016/s0003-4975(00)01368-0.

40. Rigatelli G, Carraro U, Barbiero M, Zanchetta M, Dimopoulos K, Cobelli F, Riccardi R, Rigatelli G. Activity-rest stimulation protocol improves cardiac assistance in dynamic cardiomyoplasty.Eur J Cardiothorac Surg. 2002 Mar;21(3):478-82. doi: 10.1016/s1010-7940(01)01152-6.

41. Rigatelli G, Rigatelli G, Barbiero M, Cotogni A, Bandello A, Riccardi R, Carraro U. "Demand" stimulation of latissimus dorsi heart wrap: experience in humans and comparison with adynamic girdling. Ann Thorac Surg. 2003 Nov;76(5):1587-92. doi: 10.1016/s0003-4975(03) 00759-8.

42. Rigatelli G, Carraro U, Riccardi R, Rigatelli G. Demand dynamic biogirdling: ten-year results. J Thorac Cardiovasc Surg. 2009 Jan;137(1):e58-9. doi: 10.1016/j.jtcvs.2008.06.011.

43. Hofer C, Mayr W, Stöhr H, Unger E, Kern H. A stimulator for functional activation of denervated muscles. Artif Organs. 2002 Mar;26(3):276-9. doi: 10.1046/j.1525-1594.2002.06951.x.

44. Kern H, Boncompagni S, Rossini K, Mayr W, Fanò G, Zanin ME, Podhorska-Okolow M, Protasi F, Carraro U. Long- term denervation in humans causes degeneration of both contractile and 
excitation-contraction coupling apparatus, which is reversible by functional electrical stimulation (FES): a role for myofiber regeneration? J Neuropathol Exp Neurol. 2004 Sep;63(9):919-31. doi: 10.1093/jnen/63.9.919.

45. Kern H, Salmons S, Mayr W, Rossini K, Carraro U. Recovery of long-term denervated human muscles induced by electrical stimulation. Muscle Nerve. 2005 Jan;31(1):98-101. doi: 10.1002/mus.20149;

46. Boncompagni S, Kern H, Rossini, Hofer C, Mayr W, Carraro U, Protasi F. Structural differentiation of skeletal muscle fibers in the absence of innervation in humans. Proc Natl Acad Sci U S A. 2007 Dec 4;104(49):19339-44. doi: 10.1073/pnas. 0709061104. Epub 2007 Nov 27.

47. Kern H, Carraro U, Adami N, Biral D, Hofer C, Forstner C, Mödlin M, Vogelauer M, Pond A, Boncompagni S, Paolini C, Mayr W, Protasi F, Zampieri S. Home-based functional electrical stimulation rescues permanently denervated muscles in paraplegic patients with complete lower motor neuron lesion. Neurorehabil Neural Repair. 2010 Oct;24(8):709-21. doi: 10.1177/15459683 10366129. Epub 2010 May 11;

48. Kern H, Carraro U, Adami N, Hofer C, Loefler S, Vogelauer M, Mayr W, Rupp R, Zampieri S. One year of home-based daily FES in complete lower motor neuron paraplegia: recovery of tetanic contractility drives the structural improvements of denervated muscle. Neurol Res. 2010 Feb;32(1):512. doi: 10.1179/174313209X385644.

49. Albertin G, Ravara B, Kern H, Hofer C, Loefler S, Jurecka W, Guidolin D, Rambaldo A, Porzionato A, De Caro R, Zampieri S, Pond A, Alaibac M, Carraro U. Two-years of home based functional electrical stimulation recovers epidermis from atrophy and flattening after years of complete Conus-Cauda Syndrome. Medicine (Baltimore). 2019 Dec;98(52):e18509. doi: 10.1097/MD.000000000 0018509.

50. Kern H, Carraro U. Home-Based Functional Electrical Stimulation of Human Permanent Denervated Muscles: A Narrative Review on Diagnostics, Managements, Results and Byproducts Revisited 2020. Diagnostics (Basel). 2020, 10, 529. doi: 10.3390/diagnostics10080529.

51. Available online at http://www.mdpi.com/20754418/10/8/529/s1, Video S1: Home-based Functional Electrical Stimulation (hbFES) assisted stand-up exercise.

52. Al-Amood WS, Lewis DM, Schmalbruch $\mathrm{H}$. Effects of chronic electrical stimulation on contractile properties of long-term denervated rat skeletal muscle. J Physiol. 1991 Sep;441:243-56. doi: 10.1113/jphysiol.1991.sp018749.

53. Dulhunty AF, Gage PW. Excitation-contraction coupling and charge movement in denervated rat extensor digitorum longus and soleus muscle. J
Physiol. 1985 Jan;358:75-89. doi: 10.1113/jphysiol. 1985.sp015541.

54. Kobayashi J, Mackinnon SE, Watanabe O. The effect of duration of muscle denervation on functional recovery in the rat model. Muscle Nerve. 1997 Jul;20(7):858-66. doi: 10.1002/(sici)10974598(199707)20:7<858::aid-mus10>3.0.co;2-o.

55. Nightingale EJ, Raymond J, Middleton JW, Crosbie J, Davis GM. Benefits of FES gait in a spinal cord injured population. Spinal Cord. 2007 Oct;45(10):646-57. doi: 10.1038/sj.sc.3102101.

56. Mödlin M, Mayr W, Vindigni V, Zampieri S, Boncompagni S, Protasi F, Carraro U. Stable muscle atrophy in long-term paraplegics with complete upper motor neuron lesion from 3- to 20year SCI. Spinal Cord. 2008 Apr;46(4):293-304. doi: 10.1038/sj.sc.3102131. Epub 2007 Oct 23.

57. Squecco R, Carraro U, Kern H, Pond A, Adami N, Biral D, Vindigni V, Boncompagni S, Pietrangelo T, Bosco G, Fanò G, Marini M, Abruzzo PM, Germinario E, Danieli-Betto D, Protasi F, Francini F, Zampieri S. A subpopulation of rat muscle fibers maintains an assessable excitation-contraction coupling mechanism after long-standing denervation despite lost contractility. J Neuropathol Exp Neurol. 2009 Dec;68(12):1256-68. doi: 10.1097/NEN.0b013e3181c18416.

58. Gerta Vorbová interview. Available on-line at the YOUTUBE

https://www.youtube.com/watch?v=NJ9BPLquPWw

59. Lowrie MB, Krishnan S, Vrbová G. Recovery of slow and fast muscles following nerve injury during early post-natal development in the rat. J Physiol. 1982 Oct;331:51-66. doi: 10.1113/jphysiol.1982. sp014364.

60. Connold AL, Evers JV, Vrbová G. Effect of low calcium and protease inhibitors on synapse elimination during postnatal development in the rat soleus muscle. Brain Res. 1986 Jul;393(1):99-107. doi: 10.1016/0165-3806(86)90069-6.

61. Greensmith L, Vrbová G. Neuromuscular contacts in the developing rat soleus depend on muscle activity. Brain Res Dev Brain Res. 1991 Sep 19;62(1):121-9. doi: 10.1016/0165-3806(91) 90197-q.

62. Navarrete R, Vrbová G. Differential effect of nerve injury at birth on the activity pattern of reinnervated slow and fast muscles of the rat. J Physiol. 1984 Jun;351:675-85. doi: 10.1113/jphysiol.1984.sp 015270.

63. Nógrádi A, Vrbová G. The use of a neurotoxic lectin, volkensin, to induce loss of identified motoneuron pools. Neuroscience. 1992 Oct;50(4):975-86. doi: 10.1016/0306-4522(92)90 220-v.

64. Sieradzan K, Vrbová G. Replacement of missing motoneurons by embryonic grafts in the rat spinal 
Gerta Vrbová, a guide and a friend

Eur J Transl Myol 31 (1): 9670, 2021 doi: 10.4081/ejtm.2021.9670

cord. Neuroscience. 1989;31(1):115-30. doi: 10. 1016/0306-4522(89)90034-1.

65. Gordon T. https://pubmed.ncbi.nlm.nih.gov/?term= Gordon+T\&show_snippets=off\&sort=pubdate\&siz $\mathrm{e}=100$

66. Pette D. https://pubmed.ncbi.nlm.nih.gov/?term= Pette+D\&sort $=$ pubdate\&sort_order $=$ asc $\&$ size $=100$ \&show_snippets $=$ off

67. Lomo.T. https://pubmed.ncbi.nlm.nih.gov/?term= Terje+Lomo\&show_snippets=off\&sort= pubdate \& size $=100$

68. Carraro U. https://pubmed.ncbi.nlm.nih.gov/?term $=$ Carraro+U\&show_snippets $=$ off \&sort $=$ pubdate \&size $=100$

69. Kern H. https://pubmed.ncbi.nlm.nih.gov/?term= Kern+H\&show_snippets=off\&sort=pub date \& size $=100$

70. Nógrádi A. https://pubmed.ncbi.nlm.nih.gov/?term =Nogradi+A\&show_snippets $=$ off $\&$ sort $=$ pubdate $\&$ size $=100$
71. Slawinska U. https://pubmed.ncbi.nlm.nih.gov/? term=slawinska+U\&show_snippets=off\&sort =pubdate $\&$ size $=100$

72. Scott OM, Vrbová G, Hyde SA, Dubowitz V. Effects of chronic low frequency electrical stimulation on normal human tibialis anterior muscle. J Neurol Neurosurg Psychiatry. 1985 Aug;48(8):774-81. doi: 10.1136/jnnp.48.8.774.

73. McKay WB, Stokic DS, Sherwood AM, Vrbova G, Dimitrijevic MR. Effect of fatiguing maximal voluntary contraction on excitatory and inhibitory responses elicited by transcranial magnetic motor cortex stimulation. Muscle Nerve. 1996 Aug;19(8):1017-24. doi: 10.1002/mus.880190803.

74. Hausmanowa-Petrusewicz I, Vrbová G. Spinal muscular atrophy: a delayed development hypothesis. Neuroreport. 2005 May 12;16(7):65761. doi: 10.1097/00001756-200505120-00001..

Submitted: February 8, 2021 Accepted for publication: February 8, 2021 